Elucidation of the Cross-Link Structure of Nadic-End-Capped Polyimides Using NMR of ${ }^{13} \mathrm{C}$-Labeled Polymers

Mary Ann B. Meador and J. Christopher Johnston

NASA Lewis Research Center, Cleveland, Ohio 44135-3191

Paul J. Cavano

Case Western Reserve University, Cleveland, Ohio 44106

Macromolecules

Reprinted from

Volume 30, Number 3, Pages 515-519 



\title{
Elucidation of the Cross-Link Structure of Nadic-End-Capped Polyimides Using NMR of ${ }^{13} \mathrm{C}$-Labeled Polymers
}

\author{
Mary Ann B. Meador* and J. Christopher Johnston \\ NASA Lewis Research Center, Cleveland, Ohio 44135-3191
}

Paul J. Cavano

Case Western Reserve University, Cleveland, Ohio 44106

Received May 17, 1996; Revised Manuscript Received October 14, 1996

\begin{abstract}
Solid NMR of ${ }^{13} \mathrm{C}$ isotope-labeled samples of PMR-15 was used to follow the cross-linking reaction of the nadic end cap. Some samples were labeled on one of the carbon atoms of the nadic end cap, and others on the methylene carbon atom of the methylenedianiline portion of the polymer. NMR spectra were run on these samples both before and after cross-linking. In this way, direct evidence of the major products of cross-linking under normal cure conditions is provided. The majority $(\sim 85 \%)$ of the cross-linking derives from olefin polymerization through the double bond of the end cap. Approximately $15 \%$ of the products could come from a pathway involving a retro-Diels-Alder reaction. However, all of the products could be explained by a biradical intermediate without a retro-Diels-Alder reaction. Evidence is also presented that the methylene moiety in the methylenedianiline part of the polymer chain also participates in the cross-linking, albeit to a small extent, by a radical transfer reaction. Different cure conditions (higher temperatures, longer times) could change the relative distribution of the products.
\end{abstract}

\section{Introduction}

Nadic-end-capped polyimide resins have been used extensively in aircraft engine applications as matrix materials for carbon, ceramic, or glass fiber reinforced composites. ${ }^{1}$ The attraction of these materials for such applications is their relative ease of processing over condensation polyimides. This is because, as shown in Scheme 1 for PMR-15, ${ }^{2}$ the generation of the crosslinked polymer proceeds through two steps that occur at distinctly different temperatures. The initial step, at approximately $200^{\circ} \mathrm{C}$, forms a low molecular weight polyimide oligomer through a condensation reaction. The temperature is then raised, during which time the oligomer goes through a low-viscosity melt, allowing any remaining volatile byproducts of the condensation to readily escape. The final cure step, addition crosslinking of the nadic end caps, is done under pressure at about $300^{\circ} \mathrm{C}$. This reaction occurs with little release of volatile byproducts, resulting in an essentially voidfree composite part.

Though it has been intensely studied over the last 25 years, the addition cross-linking mechanism of the nadic end caps is still not completely understood. Much of the difficulty in studying the mechanism is the intractable nature of both the intermediate oligomers and the final products of the reactions. Model compound studies have been used extensively over the years. These investigations have often given conflicting results, possibly due to the inherent limitations of model studies. A thorough review of the proposed mechanisms and past work is presented in a recent theoretical paper. ${ }^{3}$ Only the three major competing mechanisms are summarized here (Scheme 2).

The cross-linking mechanism originally proposed, 2,4 shown in pathway 1 , involves alternating copolymerization between maleimide, 5 , and cyclopentadiene, 6 , the products of a retro-Diels-Alder reaction of the end cap of oligomer 4. It is known that some retro-Diels-

\footnotetext{
* To whom correspondence should be addressed.

Abstract published in Advance ACS Abstracts, February 1 , 1997.
}

Scheme 1. Reaction Scheme for Production of PMR-15
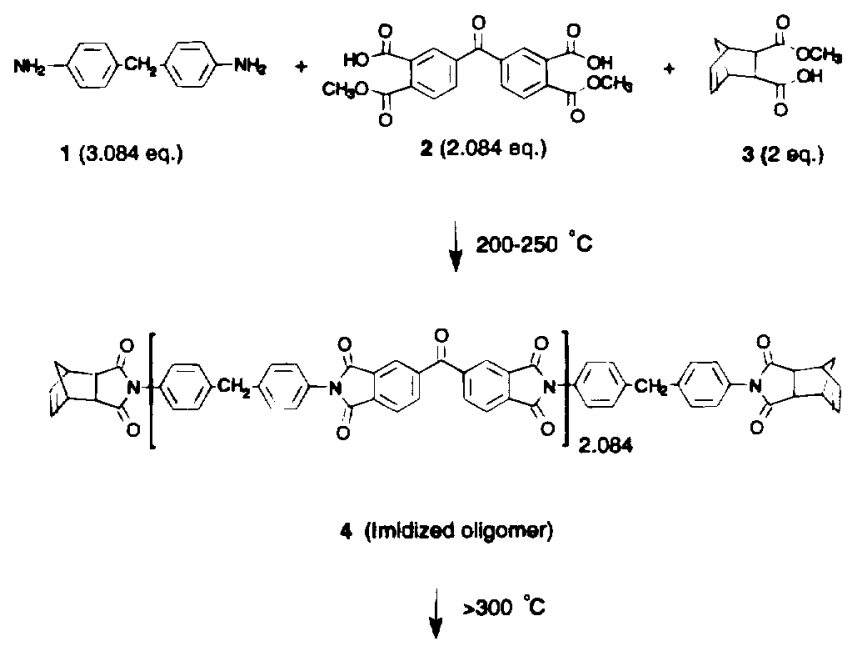

Fully crosslinked PMR-15

Alder reaction of the end cap occurs because evolution of cyclopentadiene can be detected during cure. ${ }^{5}$ However, whether or not the retro-Diels-Alder reaction is critical to the cross-linking has been the subject of much discussion over the years. ${ }^{6}$

Pathway 2 was originally proposed by Wong and Ritchey from model compound studies using $N$-phenylnadimide. ${ }^{7}$ They proposed that any 6 formed in the retro-Diels-Alder reaction could undergo Diels-Alder reaction with another nadimide end cap, to give 8 in any of eight possible stereoisomeric forms. Further, they proposed that cross-linking proceeds primarily through the double bonds of 4,8 , and maleimide 5 , in random fashion.

The difficulty with pathway 1 or 2 is that no initiator is proposed for polymerization. In pathway 3 , it is proposed that the reaction proceeds through polymerization of the double bond of 4 initiated by biradical 9 . Recently, Iratcabal and $\mathrm{Cardy}^{3}$ presented theoretical 
Scheme 2. Proposed Mechanisms for Cross-Linking

Pathway 1<smiles>Cc1ccc(N2C(=O)C3C4C=CC(C4)C3C(=O)N(c3ccc(C)cc3)C2=O)cc1</smiles>

Pathway 2

4

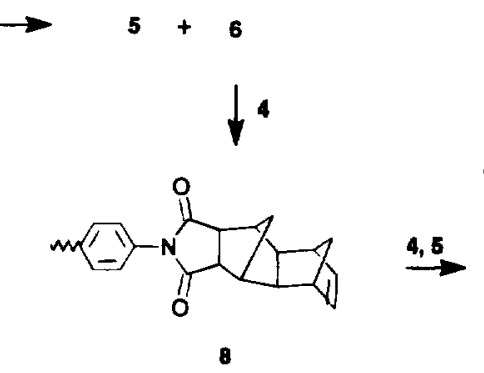

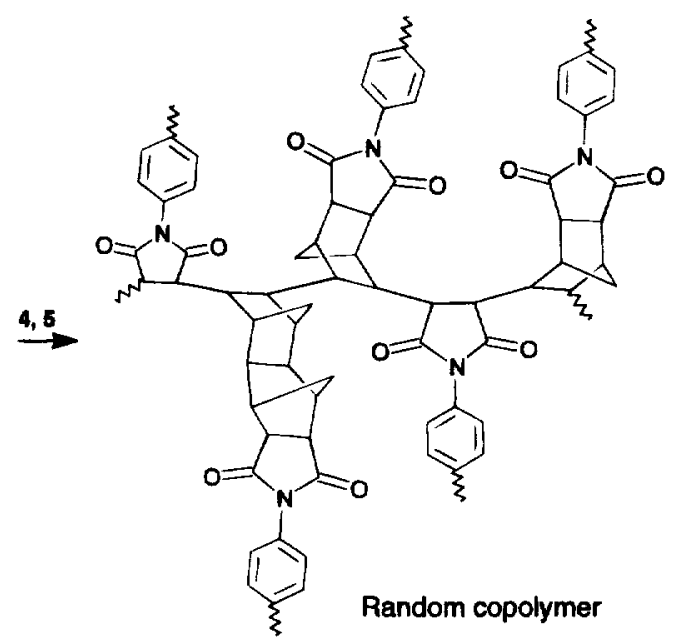

Pathway 3

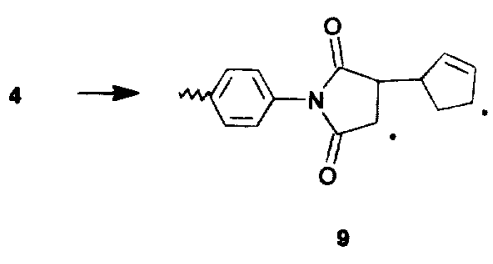<smiles>C[13CH3]</smiles><smiles>Cc1ccc(N2C(=O)C3C4CC(C3C2=O)C2C4C(=O)N(c3ccc(C)cc3)C(C3C=CC(C)C3)C3C4CC(C5C(=O)N(c6ccc(C)cc6)C(=O)C45)C23)cc1</smiles>

Homopolymer

arguments for the presence of such a biradical intermediate in these systems. Biradical 9 could also serve to initiate reaction in pathway 1 or 2 .

In this study, we wished to more clearly determine the structure of the cross-linked polymer. We followed the molecular level changes occurring on cross-linking by nuclear magnetic resonance spectroscopy (NMR) of solid samples of PMR-15. By labeling the polymers in selected sites with ${ }^{13} \mathrm{C}$, we were able to observe the reactions occurring directly, without having to use model compounds. Labeled polymer samples were analyzed by solid NMR before and after curing. Corresponding natural abundance samples were also analyzed. By subtracting the spectra of the natural abundance material from the otherwise identical spectra of the ${ }^{13} \mathrm{C}$-labeled material, we can observe the changes due only to the labeled resonances. ${ }^{8}$ Hence, the chemical changes occurring in the actual polymer during cure are more easily discerned. This method provides direct spectral evidence of the products formed during the cross-linking of PMR-15. In addition, the changes can be monitored one carbon atom at a time, providing both more easily interpretable and more conclusive evidence than natural abundance ${ }^{13} \mathrm{C}$ NMR.

\section{Experimental Section}

General Information. Benzophenonetetracarboxylic dianhydride (98\%), 2, 4,4'-methylenedianiline (97\%), 1, and 5-norbornene-2,3-dicarboxylic anhydride (98\%) were purchased from Aldrich Chemical Co. and used without further purification. ${ }^{13} \mathrm{C}$ isotopically-labeled 4,4'-methylenedianiline and 5-norbornene-2,3-dicarboxylic anhydride (labeled as shown in Chart 1) were obtained from Isotec, Miamisburg, $\mathrm{OH}$, and used without further purification.

Preparation of Imidized Oligomers. Synthesis of the isotope-labeled imidized oligomers, and the unlabeled oligomers used for direct comparison, were carried out on a $1.5 \mathrm{~g}$ scale. In a typical procedure, 5-norbornene-2,3-dicarboxylic anhydride $(0.328 \mathrm{~g}$ (or $0.332 \mathrm{~g}$, if labeled), $2 \mathrm{mmol}$ ), and $3,3^{\prime}, 4,4^{\prime}$-benzophenonetetracarboxylic dianhydride $(0.672 \mathrm{~g}$, $2.084 \mathrm{mmol}$ ) were refluxed in $5 \mathrm{~mL}$ methanol for $2 \mathrm{~h}$. The clear solution was cooled, and 4,4'-methylenedianiline, 1 (0.611 $\mathrm{g}$ (or $0.614 \mathrm{~g}$, if labeled), $3.084 \mathrm{mmol}$ ), was added. The 
Scheme 3. Possible Participation of Methylene Carbon in the Cross-Linking<smiles>[Y6]c1ccc([AsH2]c2ccc([C+])cc2)cc1</smiles><smiles></smiles><smiles>[Z]c1ccc([AsH]([R])c2ccc(C)cc2)cc1</smiles>

Chart 1. PMR-15 Oligomers Showing Positions Labeled with ${ }^{18} \mathrm{C}$<smiles>CCC(=O)N1C(=O)[C@@H]2C3C=C[C@H](C3)[C@H]2C1=O</smiles>

Endcap tabeled

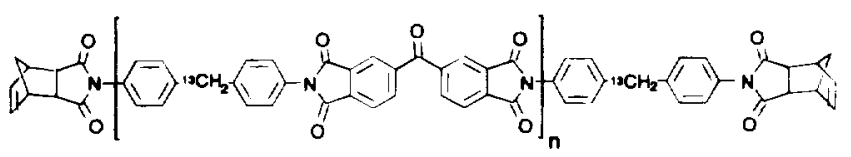

Methylene labeled

methanol was removed from the resulting yellow solution by rotary evaporation at $35^{\circ} \mathrm{C}$ to give a yellow foam. The foam was gently crushed to a coarse solid which was imidized in an air-circulating oven at $200^{\circ} \mathrm{C}$ for $2 \mathrm{~h}$ followed by an additional $0.5 \mathrm{~h}$ at $230^{\circ} \mathrm{C}$. The dark yellow solid was finely ground with a mortar and pestle to give a powder that was fully imidized, as evidenced by NMR and FT-IR.

Neat Resin Molding. A $1.27 \mathrm{~cm}$ i.d. hardened tool-steel die was used for all disk moldings. Mold surfaces were treated with a silicone-containing commercial release agent (Frecote44, Dexter Corp.). A hydraulic press, with electrically heated platens and a maximum capacity of 12 tons, was used to apply pressure and provide heat to the molding tool.

Imidized oligomers were examined by TGA and DSC techniques to identify major transitions and any unusual weight loss events. Mold cycle final temperature, rise rate, and pressure conditions were based both on these results and on a knowledge of the processing of unmodified PMR-15 oligomers from various sources.

In a typical procedure, press platens were preheated to 280 ${ }^{\circ} \mathrm{C}$, and a room temperature die, containing the imidized powder, was placed in the press. A charge weight of $0.3-0.4$ $g$ of powder was typical. To permit any residual gas evolution, mechanical stops were used to prevent the application of pressure on the part until a die temperature of $280{ }^{\circ} \mathrm{C}$ was reached. At this point, the stops were removed and a nominal pressure of 200 psi was applied. The temperature was ramped to $315^{\circ} \mathrm{C}$ over approximately $20 \mathrm{~min}$. This temperature was maintained for $1.5 \mathrm{~h}$, after which time the die was allowed to cool to below $232{ }^{\circ} \mathrm{C}$. At this temperature, it was taken out of the press, and the neat resin disk removed while still warm. In all cases, a high-quality neat resin disk with minimum surface flaws was produced.

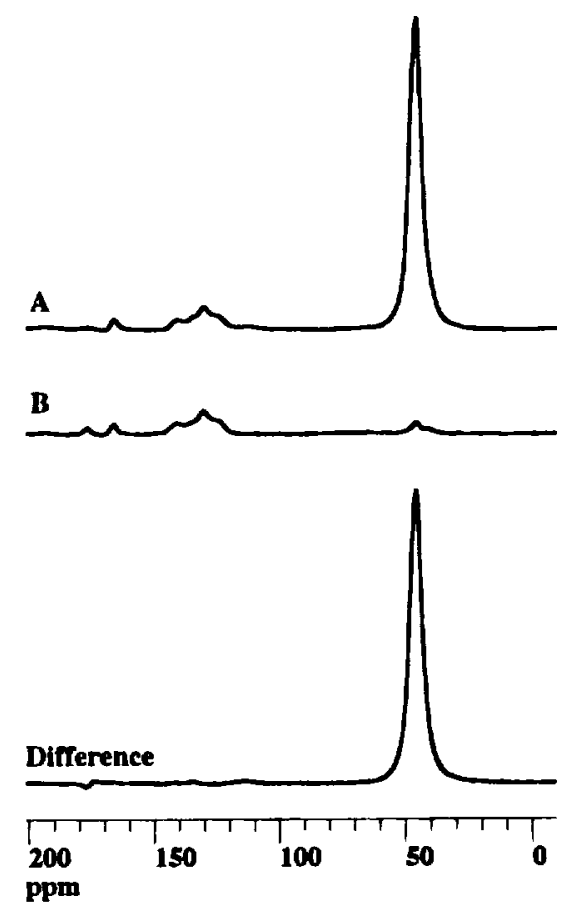

Figure 1. Solid ${ }^{13} \mathrm{C}$ NMR of (A) nadic-labeled PMR-15 molding powder and (B) unlabeled PMR-15 molding powder and (bottom) the difference spectrum (spectrum A - spectrum B) showing only ${ }^{13} \mathrm{C}$-labeled resonance.

NMR. ${ }^{13} \mathrm{C}$ NMR spectra were obtained on a Bruker AM300 fitted with a high-power solids attachment and controlled by a Tecmag mAcSPECT Data system running MacNMR 5.1 software. Solid polymer samples were run using cross polarization with magic angle spinning at $5 \mathrm{kHz}$ (CP-MAS). A pulse sequence for spinning side-band suppression was also employed. The spectra were externally referenced to the carbonyl of glycine (196.1 ppm relative to tetramethylsilane). Isotopeenriched spectra are shown as difference spectra, obtained by subtracting the corresponding natural abundance spectrum prepared and aged in the same way. Care was taken to ensure that identical conditions were used for running both labeled and unlabeled spectra. Consequently, the difference spectra contain only labeled resonance peaks.

\section{Results}

Two ${ }^{13} \mathrm{C}$-enriched oligomers of PMR-15, labeled as shown in Chart 1, were prepared. Sites for ${ }^{13} \mathrm{C}$ labeling were chosen on the basis of previous conjecture discussed above about the cure mechanisms. Nadic end cap 4 was tagged on the carbon atoms $\alpha$ to the carbonyls. Any carbons in the end cap could have been tagged and would serve to differentiate between the different reaction pathways. These particular carbons were chosen because if curing proceeds through certain pathways, i.e., loss of cyclopentadiene by reverse DielsAlder reaction (pathway 1), they would be least vulnerable to being lost from the material in a volatile byproduct. The $\mathrm{CH}_{2}$ carbon of methylenedianiline (MDA), 1, was labeled because if the reaction proceeds through free radical polymerization through the double bond (pathway 3), this carbon can participate in the curing by radical transfer. In addition, it has been suggested that this carbon may undergo oxidation during the cure. 9

An NMR spectrum of natural abundance PMR-15 molding powder is shown in Figure 1 (middle) along with that for the nadic ${ }^{13} \mathrm{C}$-labeled molding powder (top). Subtraction of the unlabeled from the labeled spectrum gives the difference spectrum (bottom) that shows only the peak for the labeled resonance at $46 \mathrm{ppm} .^{10}$ 
Table 1. Predicted Chemical Shifts of Nadic Carbons in Labeled Structural Moieties Postulated from Each of the Three Pathways for Cured PMR-15

$$
\text { (1) }
$$

A

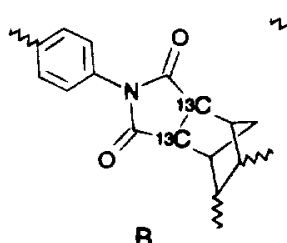

$\mathbf{B}$

\begin{tabular}{ccc}
\hline $\begin{array}{c}\text { proposed } \\
\text { mechanism } \\
\text { of cross-linking }\end{array}$ & $\begin{array}{c}\text { possible structure } \\
\text { of cross-links } \\
\text { containing } \\
\text { labeled carbons }\end{array}$ & $\begin{array}{c}\text { predicted } \\
\text { chemical shifts } \\
\text { (ppm) of } \\
\text { labeled carbons }\end{array}$ \\
\hline pathway 1 & A & 42 \\
pathway 2 & A & 42 \\
& B & 49 \\
pathway 3 & C & $45-46$ \\
& A & 42 (trace) \\
& B & 49 (main product)
\end{tabular}

${ }^{a}$ Positions of labeled carbons are marked as ${ }^{13} \mathrm{C}$ in structures.

The possible products of cross-linking of the labeled portion of the nadic end cap from each of the proposed mechanisms are shown in Table 1 , along with the chemical shifts predicted for the labeled carbons. The chemical shift of the labeled carbon in $A$ is predicted on the basis of the known chemical shift for the corresponding carbon in polymerized bis(maleimides) shown below. ${ }^{11}$

The predicted chemical shift for product B is based on model compounds reported by Milhourat-Hammadi et al. ${ }^{9}$ The authors reported the chemical shift of the corresponding carbon in the bis(nadimide) of MDA as $44.85 \mathrm{ppm}$ in solution. On hydrogenation of the nadic double bond, this carbon is shifted to $48.3 \mathrm{ppm}$, a change of approximately $3 \mathrm{ppm}$. This change from $\mathrm{sp}^{2}$ to $\mathrm{sp}^{3}$ hybridization is similar to that expected if cross-linking occurs through the nadic double bond. Thus, the labeled peak at $46 \mathrm{ppm}$ in the prepolymer should shift to 49 ppm in product $B$. The chemical shift of product $C$ is based on model compound studies by Wong and Ritchie. ${ }^{6}$

As summarized in Table 1, the labeled product of pathway 1 would be A. Thus, the NMR spectrum of the cured polymer, if the reaction proceeds through pathway 1 , would probably consist of a single resonance at approximately $42 \mathrm{ppm}$. Pathway 2 would result in a

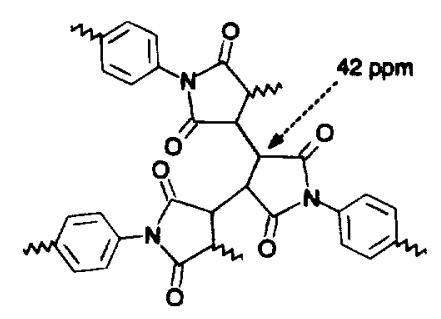

mixture of A, B, and C, with no prediction of the relative amounts of each product, except that there cannot be more $C$ than $A$. The major product of pathway 3 would be $B$. Hence, the labeled spectrum of the cured polymer, if reaction proceeds through pathway 3 , would consist mainly of a single resonance at approximately $49 \mathrm{ppm}$ and a smaller resonance at approximately $42 \mathrm{ppm}$.

Difference spectra of uncured and cured end caplabeled samples are shown in Figure 2. The spectra show only slight broadening and a small change in peak position from 46 to $48 \mathrm{ppm}$ on curing. This strongly indicates that cross-linking does not proceed through

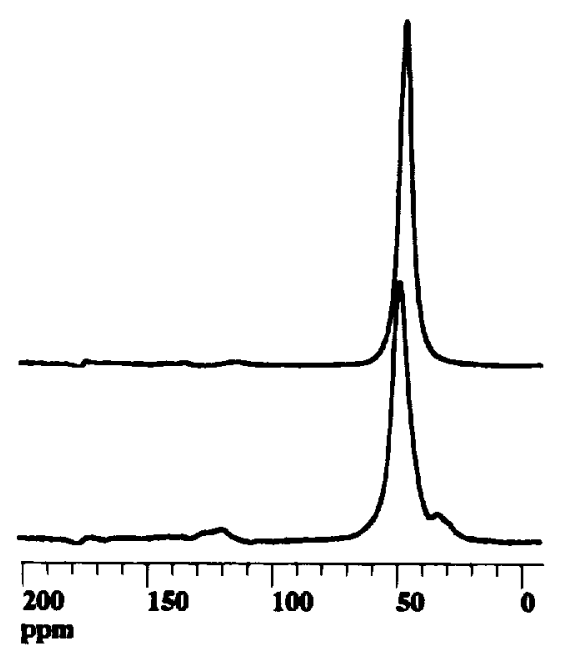

Figure 2. Difference spectra of nadic-labeled PMR-15 shown (top) after imidization and (bottom) after cross-linking.

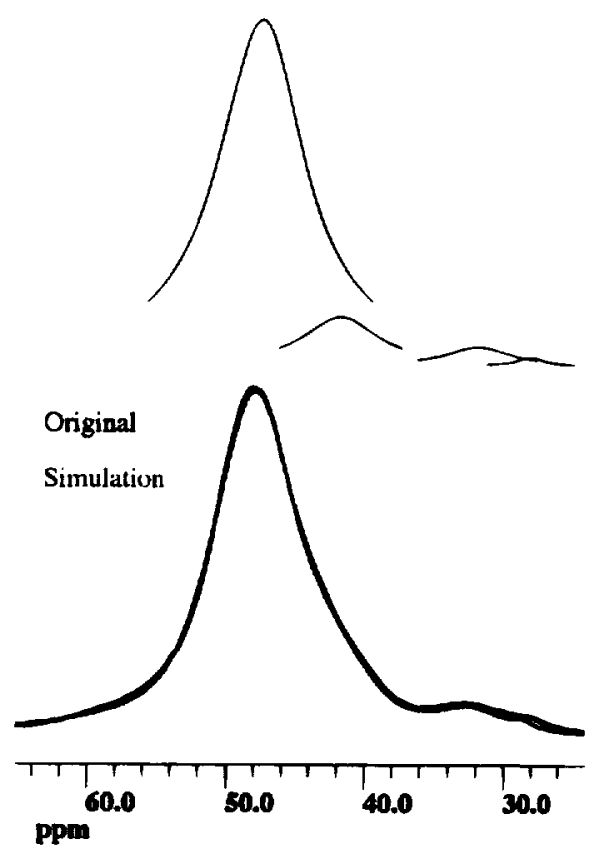

Figure 3. Expanded region of nadic-labeled spectrum of fully cross-linked PMR-15 plotted with simulated spectrum (lines used in spectrum deconvolution shown at the top).

pathway 1. It is more difficult to distinguish between pathways 2 and 3.

Figure 3 shows the difference spectrum of the cured polymer labeled on the end cap, expanded between 20 and $70 \mathrm{ppm}$. This expanded region shows that the broad resonance at $48 \mathrm{ppm}$ is not symmetric. In fact, using line deconvolution, two peaks fit this broad resonance quite well. A large peak at $48 \mathrm{ppm}$ can account for approximately $85 \%$ of the peak area, and a much smaller peak at $43 \mathrm{ppm}$ can account for about $10 \%$ of the peak area. In addition, there are some very small, broad resonances between 28 and 35 ppm, accounting for approximately $5 \%$ of the area. The individual peaks used in the fit are shown in Figure 3 (top). The resulting simulated spectrum, a sum of the fitted peaks, is shown in Figure 3 (bottom) plotted with the experimental spectrum. The two spectra are nearly identical.

Though very small compared to the peak at $48 \mathrm{ppm}$, the broad resonances between 28 and 35 ppm must have come from nadic carbons labeled in the starting material. They are most likely labeled carbons from a 


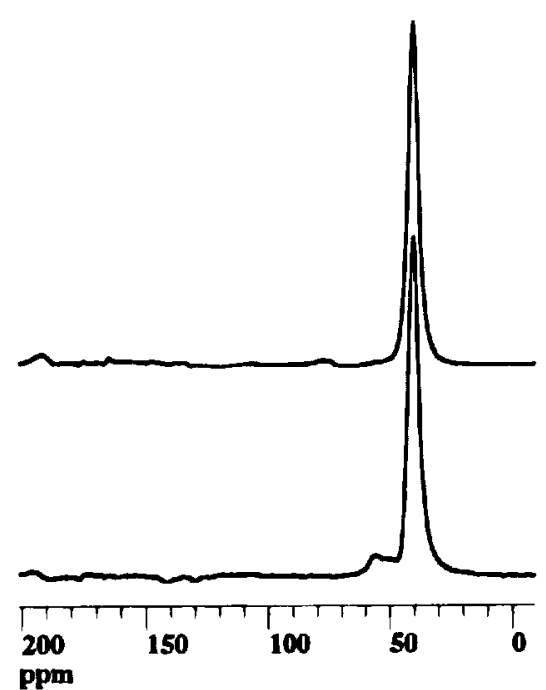

Figure 4. Difference spectra of MDA-labeled PMR-15 shown (top) after imidization and (bottom) after cross-linking.

structure such as $\mathrm{D}$, shown below. The corresponding

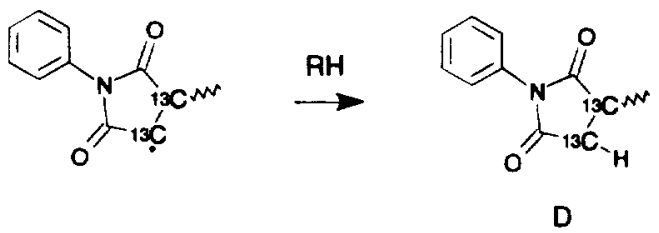

carbon in $N$-phenylsuccinimide has a reported chemical shift of 28.07 ppm. $^{5}$ It is reasonable to predict that the alkyl-substituted D could be up to $7 \mathrm{ppm}$ higher. Such a product could arise as a termination product by transfer of a hydrogen from elsewhere in the polymer chain to the radical shown.

The product distribution may differ for different cure conditions, but the analysis of the NMR clearly shows that the dominant cross-linking products under standard cure conditions derive from polymerization of the double bond of 4 (pathway 2 or 3 ). The broad peak at $48 \mathrm{ppm}$ can contain structures $\mathrm{B}$ and $\mathrm{C}$, as well as starting material. ${ }^{13}$ As stated previously, this peak accounts for about $85 \%$ of the labeled material in the cross-linked polymer. Only about $15 \%$ of the labeled products come from either maleimide 5 or biradical 9 (structures $\mathrm{A}$ and D). This means that, at the most, the retro-Diels-Alder reaction occurs only about $15 \%$ of the time, and formation of 8 can consume, at the most, $15 \%$ of 4 . Therefore, structure $\mathrm{C}$ from polymerization of 8 occurs only up to $15 \%$ of the time, and structure $B$ accounts for the majority of the peak at $48 \mathrm{ppm}$. It should be noted that the peaks for structures $A$ and $D$ can come entirely from biradical 9 , without the occurrence of a retro-Diels -Alder reaction. Thus, occurrence of $\mathrm{C}$ can be much less than $15 \%$.

Difference spectra of MDA-labeled PMR-15 before and after curing show very little change in the methylene carbon (Figure 4). The spectra do not show any methylene oxidation on curing, as has been proposed from model compound studies. ${ }^{8}$ However, a very small peak at $60 \mathrm{ppm}$ does appear after the curing. This may be due to cross-linking of the methylene carbon through a radical transfer reaction, as shown in Scheme 4.
The methylene carbon of MDA is an excellent source for hydrogen transfer because of formation of a stable diphenylmethyl radical intermediate. New carboncarbon bond formation at the methylene would give chemical shifts in the range of 55-65 ppm. This is a very minor contribution $(<5 \%)$; for the most part, the MDA does not participate in the curing. However, the presence of such a product is consistent with a free radical polymerization mechanism.

\section{Conclusions}

We have shown direct spectral evidence that the major products of cross-linking of the nadic end cap in PMR-15, under normal cure conditions, derive from olefin polymerization through the double bond of 4 (pathway 3 ). Only $15 \%$ of the products, at the most, could come from a retro-Diels-Alder reaction (pathway 1 or 2). However, while the retro-Diels-Alder reaction would explain the presence of these minor products, their presence does not require it. All of these products could come from biradical 9 . Different cure conditions (higher temperatures, longer times) could change the relative distribution of the products.

We have also presented evidence that the methylene of MDA participates in the cure, albeit to a small extent, as a site for radical transfer. This indicates that the cross-linking is a free radical process.

Knowledge of the cross-linking mechanism and the resulting molecular structure is not merely necessary for understanding how to cure the polymer system. It is also an important first step in interpreting the degradation reactions occurring in the end caps. We are extending this study by using the cured ${ }^{13} \mathrm{C}$-labeled polymers to follow the oxidative degradation that occurs when these materials are exposed to high-temperature environments.

Acknowledgment. The authors would like to thank Mr. Daniel Schieman, NYMA Corp., for providing thermal analysis and liquid chromatography of the molding powders.

\section{References and Notes}

(1) Meador, M. A.; Cavano, P. J.; Malarik, D. C. Proc. Annu. ASM/ESD Adv. Composites Conf., 6th 1890, 529-539.

(2) Serafini, T. T.; Delvigs, P.; Lightsey, G. R. J. Appl. Polym. Sci. 1972, 16, 905-915.

(3) Iratcabal, P.; Cardy, H. J. Org. Chem. 1995, 60, 6717-6730.

(4) Burns, E. A.; Jones, R. J.; Vaughn, R. W.; Kendrick, W. P. TRW-11926-6013R.0-00; TRW Systems Group: Cleveland, OH, Jan 1970. Also NASA CR-72633, 1970.

(5) Hay, J. N.; Boyle, J. D.; Parker, S. F.; Wilson, D. Polymer $1989,30,1032$.

(6) For example, see: Wilson, D. Br. Polym. J. 1988, 20, 405416.

(7) Wong, A. C.; Ritchey, W. M. Macromolecules 1981, 14, 825831.

(8) Swanson, S. A.; Fleming, W. W.; Hofer, D. C. Macromolecules $1992,25,582-588$.

(9) Milhourat-Hammadi, A.; Gaudemer, F.; Merienne, C.; Gaudemer, A. J. Polym. Chem. 1994, 32, 1593.

(10) Milhourat-Hammadi, A.; Gaudemer, F.; Merienne, C.; Gaudemer, A. J. Polym. Chem. 1991, 29, 1347.

(11) Grenier-Loustalot, M.-F.; Gouarderes, F.; Joubert, F.; Grenier, P. Polymer 1983, 34 (18), 3848.

(12) W. B. Alston, R. E. Gluyas, and W. J. Snyder (NASA TM$105629,1992)$ presented evidence that there is approximately $10-15 \%$ unreacted end cap remaining after cure.

MA9607170 
